\title{
FUEL POLICY FOR BRITAIN
}

$\mathrm{O}^{\mathrm{N}}$ J January 22, 1965, Mr. F. Lee, the Minister of Power, told the House of Commons that he was undertaking a general review of fuel policy and had already initiated discussions with the chairman of the mationalized fuel industries. To assist consultation on a wider basis he was setting up an Energy Advisory Council. This Council would consider and advise him about the energy situation and outlook, and about plans and policies of the fuel and power industries in relation to national objectives for economic growth. At the end of June he told the British Electrical Power Convention at Brighton that he expected the results of this review of fuel policy to be ready soon. At the same time, he asked the industry to increase capacity to the point where reasonable, but not excessive margins, were secured. Moreover, he asked the industry to do this for the lowest practical demands on real resources and a very substantial use of selfgenerated funds, absorbing wherever possible the increases in operating costs so that prices to consumers remained stable. Concerning co-operation between the nationalized fuel and power industries in research and development, Mr. Lee said in the House of Commons on July 13 that he had already approached the industries; the National Coal Board and the Central Electricity Generating Board had for some time had a research liaison committeo. The Gas Council had now joined with them to form a joint Liaison Committee for research and development so that their scientific potential might be used to the fullest advantage. The primary, though not the exclusive, objective was to improve the technology of utilizing coal. Mr. Lee said that the research programmes of the three industries were extensive, but he was bringing them into closer co-operation.

In view of all this a Broadsheet, Questions of Fuel Policy, issued by Political and Economic Planning*, is of some special interest. The Broadsheet starts by comparing the terms of reference of the Energy Advisory Council with the instructions given to the Ridley Committee on National Policy for the Use of Fuel and Power Resources when it was established in 1951. It points out that any recommendations the new Council may be able to agree on as to national policy are likely to represent, at the best, the highest cornmon factor of agreement between existing vested interests. The Ridley Committee, on the other hand, was an independent group of public men, economists and technologists, examining the fuel industries rather than representing them, and was more likely to be free to formulate fresh policy in a way that the new Energy Advisory Council could not be expected to do. This in itself makes the independent review in this Broadsheet of the greater interest, although it must be admitted that in practice the advice of the Ridley Committeo was not taken very seriously.

The Broadsheot notes that in 1964 Britain used primary energy equivalent to about 285 million tons of coal. Of this total about 187 million tons was actually coal; petroleum products accounted for about 93 million tors of coal equivalent, of which some 30 million tons was rond- or air-transport fuel or used in refineries. Of the remaining general fuel used, coal accounted for nearly three-quarters compared with nearly 90 per cent in 1951 . In absolute terms, coal consumption in 1964 was 20 million tons less than in 1951. Over the same period, the consumption of oil as a general fuel rose about five times to some 55 million tons. So far as total fuel consumption is concerned, the forecasts of the Ridley Committee in 1952 for fuel consumption during the

* Planning, 31. No. 489 (June 1965): Questions of Fuel Policy. Pp. 183218. (London: Political add Economic Planning, 1965.) 6s. period 1959-63 were fairly well confirmed (coal providing, however, only some 70 per cent of the total instead of 95 per cent, as forecast). Apart from the switch to oil there has been a further decline in the direct use of coal, and more and more of the final consumption of this fuel is now in the form of electricity.

On the framework of present-day policy, P.E.P. points out that imports of coal are subject to licensing and in practice no licences are granted; moreover, import licences have not been granted for any increased imports of Russian oil. Since I961 a fairly high excise duty of almost $£ 2$ a ton has been imposed on fuel oil and other oil products sold in the general energy market, while some restraint has at times been placed on the development of electricity generation from oil. Nuclear energy constitutes another factor and the Government has also abolished the customs duty on methane, which has slightly improved the economics of the scheme for importing liquefied natural gas from Algeria.

Considering new factors in the forecasts for the con. sumption of fuel, the Broadsheet points out that the forecasts and investment programmes of the major fuel industries represent, even over the short term, a higher total fuel consumption than is generally forecast-as has been pointed out by the National Economic Develop. ment Council. Forecasting demand for fuels is fairly hazardous in the commercial or technical sense beyond the 7-10 year period affected by decisions regarding investment that must be taken in the next $2-3$ years. Petroleum exploration in the North Sea is particularly hazardous, and however welcome might be the impact of North Sea gas to upset established forecasts, it may not be an economic proposition. A more practical factor in present calculations is the firmer offer of cheap nuclear power. The rapid downward revision of nuclear costs could mean a much higher rate of commissioning of nuclear plant in tho construction programmes of the supply industry by 1975 than has so far been envisaged, and in consequence an earlier levelling off in the demand for coal by power stations.

A working group of P.E.P. which is considering the energy situation and the kind of national fuel policy most suitable for Britain in the 'sixties expects to publish a full-seale report by the autumn of 1965 . In the meantime, the Broadsheet indicates some of the problems which must face those responsible for formulating policy in this field. First, it points out there is the question of whether fiscal policies, such as the levying of a fuel tax on oil used in power but not on oil used in gas manufacture, should be altered so as to favou gas less. Altematively, should gas be assisted to take over more of the demand for space heating and electricity discouraged in this sector of the domostic market? Again, there is the question of whother Ministerial policy should attempt to settle the constantly vexed arguments between the two industries and their cross-accusations about the special financial incentives alleged to be offered to local authorities and other housing developers. Again, is the right balance between amenity and efficiency being struck at present in the lengthy procedure of licensing, public enquiry and the like required for the construction of electricity production and transmission equipment? Some might also be disposed to ask whether the present structure of Government is such as to enable amenity issues to be raised at a sufficiently early stage for full effect to bo given to their arguments before the electricity authorities are committed to particular schemes. Another important question is whether research and development are adequately and properly organized in these industries, 
and in particular whether the balance of activity and initiative in nuclear development between the Central Electricity Generating Board and the Atomic Energy Authority is correct. Here again questions of Government structure may also arise, particularly in respect of the position of the Ministry of Technology.

Other questions suggested for consideration in the Broadsheet are the structural division of electricity supply for England and Wales and for Scotland, and whether there is scope for forms of combined technical development between the industries, and possibly coal or oil also, that are being ignored at present because of the structural separation and competition. The Broadsheet also questions whether limits should be put to commercially competitive promotion between the nationalized fuel industries, and how far they should be obliged to keep their investment policies with the Government's forecasts of solid and other smokeless fuel requirements arisirg from application of the Clean Air Policy. The principles to be followed in permitting these nationalized industries to diversify their activities in the fields outside those in which they now operate also require definition. The Broadsheet hints plainly that the consumer is not at present adequately informed of the price trends in the various fuels. The present structure of the Ministry of Power also requires consideration in the context of how far it conduces to a sensible co-ordination of national energy policy and to objective assessments of conflicts of policy between the nationalized fuel industries.

It should also be remembered that some of the technological changes that could occur in the supply of energy would bring with them new questions about the structure of the British fuel industries. For example, if large-scale natural gas-fields were in fact found in the North Sea, the present gas industry, with its virtual monopoly and its commitment to manufacture gas at lower calorific values, might not be the ideal instrument to introduce the natural gas into the British market. Possibly a measure of competition should be introduced when gas supply becomes more and more based on the end-products of oil refining. Nor should it be without due consideration whether the cconomies of scale in supply or in transmission are as compelling, or whether monopoly is as appropriate a form of organization for gas as for electricity supply. The Broadsheet offors no answers to these problems, but it does suggest that urgent public consideration should be given to them and particularly to the determination of the right order of priorities. This is especially so in regard to what protection the fuel industry should receive, particularly British coal, and in what form.

\section{U.S. STANDARD FREQUENCY AND TIME SERVICES}

\begin{abstract}
A REVISED (1965) publication of the United States National Bureau of Standards* gives a detailed and illustrated description of the services provided by the Standard Frequency Stations now operating in Washington, Hawaii and Colorado. The first is the well-known station, $W W V$, at Greenbelt, Maryland, which has been in operation since 1933, and now provides services of radio and audio frequencies, musical pitch, time signals and the departure of these from astronomical time; propagation forecasts and geophysical alerts are also issued from $W W V$. An additional service was started from Hawaii in 1948; but this is confined to radio frequencies, time signals and their corrections. In 1963, two low-frequency transmissions were added from stations at Fort Collits, Colorado. One, $W W V B$, broadcasts continuously on the standard frequency of $60 \mathrm{kc} / \mathrm{s}$, and provides time signals and corrections, while the other, $W W V L$, broadeasts continuously on the standard frequency of $20 \mathrm{kc} / \mathrm{s}$. The frequencies of all these services are held stable in general to a few parts in $10^{11}$, and they are ultimatoly referred to the resonance frequency of caesium, which is measured in terms of ephemeris time.

All the carrier and modulation frequencies at $W W V$ and $W W V H$ are derived from precision quartz oscillators of

* United States Department of Commeree: National Bureau of Standards. Miscellaneous Publication 236: Standard Frequencies and Time Services of the
National Bureau of Standards. Pp. 8. (Washington, D.C.: Government Printing Office, 1965.) 15 cents.
\end{abstract}

high stability. These are offset from the standard by a small but precisely known amount to reduce departure between the time signals as broadcast and astronomical time, U.T.2. Although the latter is subject to unpredictable changes readily noted at this level of precision, it is expected that the present offset-150 parts in $10^{10}$ established in 1964, will remain in effect for the present calendar year (1965). For the benefit of users who wish to make direct comparisons of absolute frequencies, $W W V B$ has been transmitting on $60 \mathrm{kc} / \mathrm{s}$ with no offset since January 1, 1965.

A comprehensive description, with diagrams, of all these services is given in the report, together with details of the propagation forecasts and geophysical alerts which are disseminatod at hourly intervals. The forecast announcement tells users, in a simple code form, the condition of the ionosphere at the regular time of issue, and the quality of radio services due to propagation conditions to be expected during the next $6 \mathrm{~h}$. A series of letter symbols is used to indicate the current geophysical conditions and give notice of any outstanding solar or geophysical ovents which are expected or which have occurred in the preceding $24 \mathrm{~h}$.

The revised issue of this publication will be welcomed by all users of frequencies and time signals, as well as by research workers in the fields of radio and the geophysical and solar sciencos.

R. L. SMith-ROSE

\section{COMMERCIAL NUCLEAR POWER STATIONS IN BRITAIN}

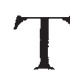

HE principal contents of the July number of the Journal of the British Nuclear Energy Society (4, No. 3; 1965) consists of the texts of the six papers contributed by members of the Central Electricity Generating Board and the South of Scotland Electricity Board and presented to the symposium on the performance of commercial nuclear power stations in the United Kingdom, which was held at the University of Leicester on June 30.

H. M. Carruthers, in his discussion of the evolution of magnox station design, points out that, in the nine years since the first Calder Hall reactor went critical, some thirty-five reactors of this basic type have been built, of which twenty-six are in Great Britain. The reactors during this period have developed from a small unit of about $40 \mathrm{MW}(\theta)$ output to one of nearly $600 \mathrm{MW}(\Theta)$ with at the same time reduced capital and generating costs. The main technical improvements in layout, shielding, refuelling methods, pressure circuit technology and fuel element design since the start of the commercial magnox programme are described in some detail.

The commissioning of a nuclear power station requires not only the setting of the plant to work safely and 